\title{
Effect of osmotic dehydration combined with citric acid on bioactive compounds in freeze-dried MD2 pineapple
}

\author{
Nur Syazwani Hanafi, ${ }^{\mathrm{a}, \mathrm{b}}$, Rosnani Hasham ${ }^{\mathrm{a}, \mathrm{b}^{*}}$, Nor Zalina Othman ${ }^{\mathrm{c}}$, Mohamad Roji Sarmidi ${ }^{\mathrm{d}}$ \\ ${ }^{a}$ Department of Bioprocess and Polymer Engineering, School of Chemical and Energy Engineering, Universiti Teknologi Malaysia, 81310, Johor \\ Bahru, Johor, Malaysia \\ ${ }^{b}$ Institute of Bioproduct Development, Universiti Teknologi Malaysia, 81310, Johor Bahru, Johor, Malaysia \\ 'Innovation Centre in Agritechnology for Advanced Bioprocessing, Universiti Teknologi Malaysia Pagoh, 84600, Pagoh, Johor, Malaysia \\ ¿Phyto Biznet Sdn Bhd, UTM-MTDC Technology Centre, Technovation Park, Universiti Teknologi Malaysia, 81300 Johor Bahru, Johor, \\ Malaysia
}

Received 25th April 2021 / Accepted 10th September 2021

\begin{abstract}
The use of freeze drying process to prolong the shelf life of food products is considered mainstream in food industries due to its capability to retain the nutritional value. Citric acid and osmotic solution were used as a pre-treatment in this study to produce high-quality dried products. Four treatment groups were observed, including untreated (control), 1\% citric acid (CA), 1\% CA with 20\% sugar solution (CAOD 20\%), and 1\% CA with 60\% sugar solution (CAOD 60\%). Physical properties such as moisture content; $\mathrm{pH}$; total soluble solid; colour value; and bioactive compounds, such as vitamin $\mathrm{C}$, total phenolic content (TPC), total flavonoid content (TFC), and antioxidant activities were evaluated in freeze-dried pineapples. The result showed that CAOD $60 \%$ demonstrated a positive effect, with the least moisture content and the lowest value of colour changes $(\Delta \mathrm{E})$ at $5.69 \pm 0.04 \%$ and $33.76 \pm 2.17$, respectively, as compared with that of other samples. In terms of phytochemical, the control and CA groups recorded higher retention of vitamin $\mathrm{C}$, TPC, and TFC compared with other osmotic dehydration samples; however, there was no significant effect $(\mathrm{p}<0.05)$ on TPC and TFC. Interestingly, CAOD 60\% possessed strong antioxidant activity, with the lowest $\mathrm{IC}_{50}$ value of $85.85 \pm 5.93$. From these findings, it was found that CAOD 60\% resulted in positive effect on both the physical qualities and preservation of antioxidant activity, making it a recommended condition for pre-treatment in fruit preservation, which is essential in ensuring both the food security aspect and maintenance of its nutritional value.
\end{abstract}

Keywords: pineapple, freeze drying, physicochemical, phytochemical, antioxidant, pre-treatment

\section{INTRODUCTION}

Ananas comosus (L.) is known as pineapple, a popular commercial fruit. Malaysian Pineapple Industry Board (MPIB) revealed twelve varieties had been planted in Malaysia. The aforementioned varieties are Morris (AC1), Sarawak (AC2), Gandol (AC3), Maspine (AC4), Josapine (AC5), Yankee (AC6), Moris Gajah (AC7), N36 (AC8), MD2 (AC9), View of Sunset (AC10), Madu Kaca (AC 11) and Keningau Diamond (AC12) (MPIB, 2021). Syahrin (2011) conducted a survey among four varieties of pineapple, which were Josapine, Maspine, Moris, and MD2, and the result showed MD2 variety has a higher consumer preference. There are five ripening stages of $\mathrm{MD} 2$ variety, which are defined by peel colour analysis, as follows: Stage 1 (mature green), Stage 2 (25\% yellow), Stage $3(50 \%$ yellow), Stage 4 (75\% yellow), and Stage $5(100 \%$ yellow) (Ding \& Syazwani, 2016). According to Ding \& Syazwani (2016), different ripening stages

*Author for correspondence: Rosnani Hasham, Department of Bioprocess and Polymer Engineering, School of Chemical and Energy Engineering, Universiti Teknologi Malaysia, 81310, Johor Bahru, Johor, Malaysia.

Email-r-rosnani@utm.edu.my 
affect different physicochemical and phytochemical of fresh MD2 pineapple. Stages 3 and 4 have a higher retention of total phenolic content and antioxidant activity than other stages. This tropical fruit has gained attention, as it can be consumed fresh or produce varieties of processed products, which can improve the economy sector (e.g., small medium enterprise) through production of pineapple juice, jam, biscuit, dried fruit, and sweets. However, similar to other fruits, fresh pineapple fruits are perishable due to its high water content, which can cause increased enzyme activities and microbial growth that are generally responsible for quality loss and fruit spoilage (Phisut, 2012). One of the oldest methods known for food preservative is lowering the water activity by drying or dehydration (Bourdoux et al., 2016). This process can reduce the product's mass, spoilage, microbiology activity, thus, increasing its shelf life (Hwa et al., 2008). Moreover, this technique is one of the crucial alternatives to reducing wastage problem due to short shelf life and postharvest loses of fruits (Lima et al., 2016).

Previous study showed that different drying techniques have been utilised for fruit dehydration, such as spray drying (Jittanit et al., 2010; Saikia et al., 2015; Rezaul et al., 2017), oven drying (Abano \& Sam-Amoah, 2011), convective air drying (Amami et al., 2017), and freeze drying (Taylor et al., 2007; Ergün \& Dirim, 2015; Wang et al., 2018). There was also information about the impact of different drying method (convective, microwave and freeze drying) on colour, phenolics content, biological activities, and kinetic drying of pineapple fruit (Izli et al., 2018). Each production showed variation on physical, biological, and biochemical properties. Drying process involves temperature, pressure, and addition of preservative, causing the disintegration of fruit tissue and therefore, influencing the compounds contained in dried products (Lon et al., 2016). Meanwhile, thermal processing technique can cause the degradation of important phytochemicals and nutrients in dried products, which can lead to colour changes during storage (Ong et al., 2012). Carotenoids ( $\beta$ Carotene) that contribute the yellow colour of fruits and vegetables can be significantly affected by these processing techniques (Khoo et al., 2011). In addition, the bioactive compound in food that is sensitive to high temperatures, such as phenolics, flavonoid (Heras-Ramírez et al., 2012), carotenoids (Fratianni et al., 2013), and ascorbic acid (Kurozawa et al., 2013; Nicoleti et al., 2007), also influence degradation, especially when thermal is applied in drying process. Freeze drying is an impressive drying method, whereby it applies the advantage of removing water from a product through sublimation (solid to vapour) without passing the liquid phase. Such method is widely used in pharmaceutical and food industries to improve stability, and it is essential for preserving important nutrients, as well as biochemical compounds in the fruits (Mat et al., 2018). However, freeze drying is an expensive unit operation that requires high cost of maintenance, and its applications are limited to industrial-scale production (Doymaz, 2009).

Although drying is one of the most frequently used processes for ensuring food stability, pretreatment, such as blanching or addition of chemical additives, prior to drying process is preferred in order to minimise the drying challenges, such as long drying period, degradation of nutrition, and poor product quality. Generally, pre-treatment decreases the initial moisture content by altering the structure of the food material, resulting in increased water diffusivity and consistency of the final dried products at a low cost (Heras-Ramírez et al., 2012). In order to minimise adverse changes during drying and storage, pre-treatment prevents darkening of the fruit surface and causes the elimination of pathogens that may lead to foodborne disease (Adepoju \& Osunde, 2017). Several chemical and physical pre-treatments can be implemented prior to drying, depending on the food to be dried and desired end product. Various pre-treatments have been used in previous research, with consideration of the food to be dried and its end use, including chemical agents involved, such as sugar, salt, potassium carbonate, citric acid, and ascorbic acid (Doymaz, 2009). Adepoju \& Osunde (2017) reported that dried mango sample can retain its nutrient content, such as vitamin $C$ and $\beta$ - carotene, after dipping in honey solution, compared to ascorbic acid treated, blanched, and control samples. Other than that, physical pre-treatment such as blanching, steam, ohmic heat, microwave, freezing, and ultrasonic field are widely used for 
improving the quality of fruits or vegetables (Deng et al., 2017). The freeze-dried quince slices treated with ultrasound for 20 min showed a positive result, having retained the highest bioactive compound and enhanced physical properties compared with that of untreated sample (Yildiz \& Izli, 2019).

According to Paula and Landim (2016), most researchers focus on the kinetic study in terms of water loss and solid gain of dried fruit, with only a few studies examining the effect of the process on the functional properties of osmo-dehydrated food. The technique of eliminating unbound moisture from a food by dipping it in a hypertonic solution is known as osmotic dehydration. Typically, the water from product (hypotonic solution) diffuses to the osmotic solution (hypertonic solution) through semipermeable membrane until equilibrium is reached (Zzaman et al., 2021). In general, the osmotic treatment in food aims to preserve sensory, increase the quality of dehydrated food, and retain the bioactive compounds. It also minimises injury during drying process to ensure stability of the final product. The effect of mass transfer rates on solution and solid depend on solute type and concentration, agitation and temperature of the osmotic solution, solid-solution ratio, and the shape and size of the food, as reported by Almeida et al. (2015). Organic acids, such as citric acid, are widely used in food industry to suppress peroxidase and polyphenol oxidase, as well as to avoid browning of fruits and vegetables by acidification (Zhou et al., 2018). It is well known that the acidic $\mathrm{pH}$ of citric acid can be very effective in controlling microorganisms in cut fruits, since it can significantly slow down the oxidation process (Zapata et al., 2011). It is crucial to understand the effects of pre-treatment on freeze-dried fruit in order to ensure the highest possible stability of the phytochemical constituents of food materials. To the authors' knowledge, there are only a few reports on the effect of osmotic solution containing citric acid on the phytochemical content of freeze-dried MD2 pineapple. Therefore, this work aims to establish the effect of different concentration of osmotic solution combined with citric acid pretreatment on the physicochemical properties and phytochemical content of freeze-dried MD2 pineapple.

\section{MATERIALS AND METHODS}

\section{Sample preparation}

Fresh and ripe pineapple (Ananas comosus (L.)) of MD2 variety was purchased at Lembah Mata Naga, Ayer Hitam, Kluang, Johor, Malaysia. The fruits were washed, peeled, and cut into triangle shapes of 5-mm thick slices for quick drying. After cutting, the samples were immediately processed. The total soluble solids (TSS) content of fresh MD2 pineapples evaluated using a refractometer (PAL-3, Atago, Japan) was $16.02 \pm$ $0.96^{\circ}$ Brix, whereas the $\mathrm{pH}$ measured using a $\mathrm{pH}$ meter (S475, Mettler Toledo, Japan) was $4.48 \pm$ 0.03 , and the initial moisture content was determined to be $80.44 \pm 7.95 \%$ by oven drying at $105^{\circ} \mathrm{C}$ until constant weight was achieved (AOAC, 1990).

\section{Pre-treatment}

Pre-treatment of fresh pineapple slices was carried out by soaking them in different solutions, as previously described by Karim et al., (2008). Approximately $400 \mathrm{~g}$ of pineapple flesh samples were immersed into $800 \mathrm{~mL}$ of $1 \%$ citric acid (CA) combined with different concentrations of sugar solution $(0 \%, 20 \%, 60 \%)$. Each sample was treated for $5 \mathrm{~min}$ at ambient temperature before freeze drying; one sample was untreated and served as the control.

\section{Freeze drying}

After the treatment process, both the treated and control pineapple slices were spread on the trays and placed onto a single product chamber of a pilot scale freeze dryer (CUDDON FD80, New Zealand). The drying operation was carried out in three stages, which are freezing, primary drying, and secondary drying. The refrigeration conditions were designed as follows: freezing temperature of $-20^{\circ} \mathrm{C}$; sublimation temperature of $-20^{\circ} \mathrm{C}$ to $0^{\circ} \mathrm{C}$; and vacuum level of 0.34 mbar. The isothermal desorption temperature ranged from $0^{\circ} \mathrm{C}$ to $40^{\circ} \mathrm{C}$ in a vacuum of $0.060 \mathrm{mbar}$. The freeze-drying process took approximately 24 hours until the final product reached a temperature of $30^{\circ} \mathrm{C}$. 


\section{Moisture content, $\mathrm{pH}$, and total soluble sugar (TSS)}

Moisture content was determined by moisture analyser (MX50, A\&D Company). $1.0 \pm 0.1 \mathrm{~g}$ of freeze-dried pineapple was placed on the aluminium plate and dried at $140^{\circ} \mathrm{C}$ for approximately $15 \pm 3 \mathrm{~min}$. For each freeze-dried pineapple treatment, the pineapple chips was ground to form powder using a grinder (PB3203, Pensonic, Malaysia) and soaked in distilled water in a ratio of 1:5 (w/v) for $5 \mathrm{~min}$. The supernatant was then used for determination of $\mathrm{pH}$ and TSS. The $\mathrm{pH}$ was measured using $\mathrm{pH}$ meter and a single drop of the pineapple solution was placed onto the prism of the refractometer and expressed as ${ }^{\circ}$ Brix. All determinations were done in triplicate and the results were expressed as standard deviation (STD).

\section{Colour determination}

The colour parameter of fresh and freeze-dried pineapple skin colour were determined by using colourimeter (PCE-CSM 1, Spain) that is equipped with Illuminant D65 and $6-\mathrm{mm}$ measuring area in the CIE L* $\mathrm{a}^{*} \mathrm{~b}^{*}$ colour scale. $\mathrm{L}^{*}$ value measured the darkness from 0 to 100 (black to white), $a^{*}$ value measured range colour from greenness $\left(-a^{*}\right)$ to redness $\left(+a^{*}\right)$ and $b^{*}$ value measured range colour blueness $\left(-\mathrm{b}^{*}\right)$ to yellowness $\left(+b^{*}\right)$. For each treatment, ten replicates of measurements were performed and the averaged $L^{*}, a^{*}$, and $b^{*}$ values were reported. The instrument was calibrated using a standard white plate before each measurement. The total colour difference $\left(\Delta \mathrm{E}^{*}\right)$ that indicates colour change between fresh and dried samples was calculated by the following equation:

$$
\Delta E_{\left(L^{*} a^{*} b^{*}\right)}=\sqrt{\Delta L^{* 2}+\Delta a^{* 2}+\Delta b^{* 2}}
$$

where, $L^{*}, a^{*}$ and $b^{*}$ are colour coordinate while $\Delta \mathrm{L}^{*}, \Delta \mathrm{b}^{*}, \Delta \mathrm{a}^{*}$ are difference between fresh and dried values $\left(\Delta \mathrm{L}^{*}=\mathrm{L}^{*}\right.$ fresh $-\mathrm{L}^{*}$ dried, $\Delta \mathrm{a}^{*}=$ $a^{*}$ fresh $-a^{*}$ dried, $\Delta b^{*}=b^{*}$ fresh $-b^{*}$ dried).

\section{Extraction of freeze-dried MD2 pineapple}

Sample extraction was prepared according to Amami et al., (2017) with minor modification. Pineapple that had been freeze-dried (500 mg) was ground into powders using a grinder. These powders were extracted in the Digital Ultrasonic Cleaner for 20 minutes with $70 \%$ ethanol/water
(20 mL) (WUC- D06H, volume: 6 L, Korea). Afterward, the extract was centrifuged using a centrifuge (Eppendorf 5810R, Germany). Following that, the supernatant was filtered through a 0.45 micron syringe filter to remove sediment, and the extract was diluted with solvent for subsequent use. The extracts were stored at $20^{\circ} \mathrm{C}$ for 24 hours before use.

\section{Determination of vitamin $C$}

Vitamin $\mathrm{C}$ content was determined using high performance liquid chromatography (HPLC) on an Agilent 1290 Infinity II Series (Germany) equipped with a degasser, quaternary pump, and autosampler injector set to a volume injection of $20 \mu \mathrm{L}$. Separation was carried out using a YMCTriart C18 HPLC column (5 m particle size 150 $4.6 \mathrm{~mm}$ I.D., maintained at $25^{\circ} \mathrm{C}$ ) and a UVVisible diode array detector (DAD). The mobile phase used were $0.015 \mathrm{~mol} / \mathrm{L}$ potassium dihydrogen phosphate $\left(\mathrm{KH}_{2} \mathrm{PO}_{4}\right)$ buffer solution (pH: 2.6) and the ascorbic acid peaks were detected at $250 \mathrm{~nm}$. The standard used in this analysis was L-ascorbic acid with five different concentration $(10,25,50,75,100 \mathrm{mg} / \mathrm{L})$ with equation $\mathrm{y}=239.19 \mathrm{x}-294.14$ and $\mathrm{R}^{2}=0.9984$.

\section{Determination of total phenolic content}

The total phenolic content (TPC) in the extracts were quantified using the Folin Ciocalteau assay (Korekar et al., 2014) with slight modification. Gallic acid was the standard for calibration curve. $30 \mu \mathrm{L}$ of extracts or a standard solution $(0,25,50$, 100 and $150 \mathrm{mg} / \mathrm{mL}$ ) were added to a $100 \mu \mathrm{L}$ of Folin-Ciocalteu's reagent in 96 well-plate and incubated for $5 \mathrm{~min}$ at room temperature. Then, $80 \mu \mathrm{L}$ of $7.5 \% \mathrm{Na}_{2} \mathrm{CO}_{3}$ was added to the mixture and incubate them on the shaker in the dark room. The absorbance was read at $765 \mathrm{~nm}$ against blank (solvent) after $60 \mathrm{~min}$ incubation by ELISA microplate reader (SpectraMax M2e, USA). The TPC was expressed as $\mathrm{mg}$ of gallic acid equivalent per gram (GAE/g) sample dried weight and the calibration equation for gallic acid was $\mathrm{y}=$ $0.0088 x+0.1204\left(R^{2}=0.9982\right)$.

\section{Determination of total flavonoid content}

Total flavonoid content (TFC) of the extracts was estimated using the aluminium chloride colorimetric method as described by Amitabye $e t$ al. (2002) with slight modification. $100 \mu \mathrm{L}$ of 
extract was mixed with $100 \mu \mathrm{L}$ of aluminium chloride $\left(\mathrm{AlCl}_{3}\right)$ in 96 well-plate and incubated at room temperature for $10 \mathrm{~min}$. The absorbance of the solution was read at $430 \mathrm{~nm}$ using a microplate reader (SpectraMax M2e, USA). The TFC of the samples was expressed as $\mathrm{mg}$ of rutin per $\mathrm{g}$ (rutin/g) sample dry weight (DW).

\section{Antioxidant activity}

2.2-diphenyl-1-picrylhydrazyl (DPPH) free radical scavenging activity of the extract was measured according to the method described by Mohamad et al. (2009). Ascorbic acid was used as a standard. $100 \mu \mathrm{L}$ of sample extracts or standard at various concentration $(7.81-1000 \mu \mathrm{g} / \mathrm{mL})$ was filled in the 99 well-plate and $100 \mu \mathrm{L}$ of $0.1 \mathrm{mM}$ ethanolic solution of DPPH was added by using multichannel pipette. The mixture was incubated for $30 \mathrm{~min}$ at room temperature in dark place and analysed in triplicate. The absorbance was measured at $515 \mathrm{~nm}$ using ELISA microplate reader (SpectraMax M2e, USA). The control for this analysis was the DPPH solution in the absence of sample, while the blank was replace DPPH solution with 70\% EtOH. The antioxidant capacity of the extracts was expressed as $\mathrm{IC}_{50}$, which is the concentration necessary for $50 \%$ reduction of DPPH free radicals.

$$
\text { inhibition concentration }\left(I C_{50}\right)=\left[A_{0}-A_{1} / A_{0}\right] \times 100
$$

where, $A_{0}$ is the absorbance of the control and $A_{1}$ is the absorbance of the sample.

\section{Data analysis}

Data analysis were conducted using SPSS Statistics software. The result obtained from the study was represent as the mean values of duplication and the standard deviation (STD). Significance differences between the mean value was determined by one-way of analysis of variance (ANOVA) at the significant level, $\mathrm{p}<0.05$. Then, the graph and the regression line was plotted using Graph Pad Prism 8.0.2.

\section{RESULTS AND DISCUSSION}

\section{Moisture content, $\mathrm{pH}$, total soluble sugar (TSS)}

The moisture content, $\mathrm{pH}$ and TSS of freezedried MD2 pineapple were determined and the results are shown in Table 1 . Food in its natural state contain moisture, which is an ideal habitat for the growth of various pathogens. Low moisture content of food is preferable for microbiological stability, pathogen prevention, and food preservation (Ivančević et. al., 2012). The result of this study revealed that moisture content of dried pineapple decreased as the sugar solution increased. The least moisture content is found in control sample that have not been soaked in any solution $(5.27 \pm 0.36 \%)$ followed by CAOD $60 \%$ and CAOD 20\% (5.69 $\pm 0.04 \%, 6.15 \pm 0.20 \%)$, respectively and there is no significant difference $(\mathrm{p}<0.05)$. However, in comparison to other treatments, the moisture content of CA treatment $(6.36 \pm 0.29 \%)$ is significantly higher $(\mathrm{p}>0.05)$ since there is less water uptake from the fruits into the solution without sugar. In overall, pretreatment with osmotic solution has a positive effect on moisture content because it reduces the moisture content in the fruits after drying which can slow down the rate of deterioration and maintain its quality (Oyinloye \& Yoon, 2020).

The presence of $1 \%$ citric acid and varying concentrations of sugar solution induces a decrease in $\mathrm{pH}$ values that ranges between $4.05 \pm$ 0.00 and $4.18 \pm 0.01$. However, the $\mathrm{pH}$ value of the untreated control of freeze-dried pineapple $(4.26 \pm 0.03)$ was higher than CA, CAOD $20 \%$, and CAOD $60 \%$. This demonstrates that the addition of citric acid elicits a positive response by reducing the microbial count of pineapple through adjusting an acidic $\mathrm{pH}$ that is unfavourable for mould and yeast development (Zapata et al., 2011). On the other hand, osmotic solution does not give any impact or influence on $\mathrm{pH}$ value, since $\mathrm{pH}$ measured the hydrogen ion $\left(\mathrm{H}^{+}\right)$concentration in a solution. Zzaman et al. (2021) reported that the $\mathrm{pH}$ of fresh pineapple from Giant Kew was $3.44 \pm 0.01$ and the freezedried pineapple was in ranged of $3.36 \pm 0.01$ to $4.22 \pm 0.02$. This means that the $\mathrm{pH}$ value of dried pineapples was higher than the $\mathrm{pH}$ value of fresh 
pineapples because the total acidity was reduced during pre-treatment.

TSS was described as sugar content expressed in percent (Yang et al., 2011). It is the most important quality parameters used to imply the sweetness of fresh and processed agricultural food products. In this study, the TSS of fresh pineapple was $15.81 \pm 1.11^{\circ}$ Brix, which is higher than freeze-dried pineapple which range from $12.95 \pm 0.05$ to $13.22 \pm 0.34^{\circ}$ Brix and shows no significant different $(\mathrm{p}<0.05)$ between treated samples. However, Zzaman et al. (2021) reported that TSS of dried pineapple was higher than fresh pineapple as the sugar and other solid contents in the fruit become concentrated during drying. In general, the increasing of osmotic solution will increase the TSS which attributed to the uptake of more sugars and removal more water, since fruits were soaked in hypertonic solution (Kumar \& Sagar, 2014). However, the finding of this research indicate that increasing the sugar solution leads to a decrease in TSS, which contradicts the previous study. This condition may be attributed to a combination of osmotic solution and citric acid, which alters the natural process for transporting sugar or other solids into fruits.

Table 1. Effects of different pre-treatments on the physicochemical properties (moisture content, $\mathrm{pH}$, total soluble solid) of freeze-dried MD2 pineapples.

\begin{tabular}{cccc}
\hline Samples & Moisture contents (\%) & pH values & Total Soluble Solids ( ${ }^{\circ}$ Brix) \\
\hline Control & $5.27 \pm 0.36^{\mathrm{a}}$ & $4.26 \pm 0.03^{\mathrm{b}}$ & $13.22 \pm 0.34^{\mathrm{b}}$ \\
CA & $6.36 \pm 0.29^{\mathrm{c}}$ & $4.18 \pm 0.01^{\mathrm{b}}$ & $13.05 \pm 0.33^{\mathrm{ab}}$ \\
CAOD 20\% & $6.15 \pm 0.20^{\mathrm{bc}}$ & $4.05 \pm 0.00^{\mathrm{a}}$ & $13.02 \pm 0.40^{\mathrm{ab}}$ \\
CAOD 60\% & $5.69 \pm 0.04^{\mathrm{ab}}$ & $4.18 \pm 0.04^{\mathrm{b}}$ & $12.95 \pm 0.05^{\mathrm{a}}$ \\
\hline
\end{tabular}

*Mean \pm Standard deviation $(\mathrm{n}=3)$.

**Statistical analysis showing different letter $(\mathrm{a}, \mathrm{b}, \mathrm{c})$ on the same column are significantly different at $\mathrm{p}<0.05$ by Duncan multiple-range test using SPSS statistics software.

\section{Effect of pre-treatment on colour of freeze- dried MD2 pineapple}

Colour is crucial characteristic in food as consumer preference of acceptability. The deterioration of colour is characterised by severe browning, which can be enzymatic or nonenzymatic in nature (Yildiz \& Izli, 2019). The L* value colour parameter indicates the product's whiteness, with a range of values ranging from brightest white (high value) to darkest black (low value), and a stretch value of $0-100$. The parameter $a^{*}$ depicts the colour measurement spectrum of colours ranging from green (-) to red $(+)$, while the parameter $b^{*}$ depicts the colour measurement spectrum of colours ranging from blue (-) to yellow $(+)$. The colour parameters of fresh and freeze-dried pineapple chips show in Table 2 in term of lightness $\left(\mathrm{L}^{*}\right), \mathrm{a}^{*}, \mathrm{~b}^{*}$, and total colour difference $\left(\Delta \mathrm{E}^{*}\right)$. Based on the results, the value for the $L^{*}, a^{*}$ and $b^{*}$ coordinates of the fresh pineapple were $49.77 \pm 1.90,2.93 \pm 1.89$ and $30.87 \pm 2.40$, respectively.

$L^{*}$ value of pineapple slices increased significantly before and after freeze drying due to removing water by sublimation method that prevent the enzymatic browning reaction. Thus, low browning process not promoted by less oxygen and low temperature as stated by (Raquel \& Guinéa, 2012). The $L^{*}$ value of freeze-dried pineapple, either the control or treated with different concentration of sugar solution, showed no significant difference $(\mathrm{p}>0.05)$, ranging between $82.51 \pm 2.07$ and $83.62 \pm 1.90$. The increased lightness is a normal phenomenon, which occurs to other fruits or vegetables that undergo freeze drying method, as studied by Valentina et al. (2016), where the $\mathrm{L}^{*}$ values before and after freeze drying are as follows for banana $(61.62 \pm 9.40,75.69 \pm 0.85)$, apple $(73.37 \pm 1.99$, $85.43 \pm 1.15)$, kiwi $(62.01 \pm 9.58,86.60 \pm 1.27)$.

Regarding a* value (redness/greenness), the fresh pineapple $(2.93 \pm 1.89)$ showed positive value and displayed a significant increase in $\mathrm{a}^{*}$, followed by control, CAOD $60 \%$, CAOD $20 \%$, and $\mathrm{CA}$ at $-0.93 \pm 0.98,-1.43 \pm 0.55,-2.23 \pm$ 0.40 , and $-2.37 \pm 0.65$, respectively. On the other hand, the highest $b^{*}$ value (yellow/blue) was obtained for the fresh pineapple $(30.87 \pm 2.40)$ and significant difference was observed $(\mathrm{p}>$ 0.05), followed by freeze-dried pineapple of either control or treated pineapple that ranged from $24.30 \pm 0.91$ to $28.67 \pm 1.12$. The result shows $a^{*} b^{*}$ had positive values, while the $a^{*}$ value was negative value due to the less green colour and 
closer to yellowness. The changes in colour parameter of fresh and freeze-dried sample on $L^{*}$, $\mathrm{a}^{*}$, and $\mathrm{b}^{*}$ may be attributable to the duration of drying process, but freeze drying showed the least degradation of changes in colour, since this process is carried out under low temperature, as reported by Harguindeguy et al. (2019).

Natural colour appearance could be obtained via osmotic dehydration as pretreatment (Paula \& Landim, 2016). The control sample demonstrates the lowest value (33.07 \pm 2.13) of colour changes $\left(\Delta \mathrm{E}^{*}\right)$, which is considered optimal, as low values of $\Delta \mathrm{E}^{*}$ indicate little colour change from the actual colour. There are no significant difference among the control and treated samples, which ranged from $33.76 \pm$
2.17 to $34.83 \pm 1.85$. The result does not show any effect in $\Delta \mathrm{E}^{*}$, since the sample was immersed in the osmotic solution, thus, this work suggests for storage to determine the colour after some time (one to three months) to assess the difference of colour for 0 month and 3 months. According to Xiao et al. (2017), with the same storage time, osmotic dehydrated samples had significantly $(p<0.05)$ lower changes in colour than untreated samples, contributing primarily to sugar infusion into the cellular tissue and the protective effects of sugars in colour. This is predicted for treated sample with osmotic dehydration, in which conservation of colour is assumed when compared with control sample.

Table 2. Effects of different pre-treatment techniques on the colour values of freeze-dried MD2 pineapples.

\begin{tabular}{ccccc}
\hline \multirow{2}{*}{ Samples } & \multicolumn{4}{c}{ Colour values } \\
\cline { 2 - 5 } L $^{*}$ & $\mathbf{a}^{*}$ & $\mathbf{b}^{*}$ & $\mathbf{\Delta \mathbf { E } ^ { * }}$ \\
\hline Fresh fruit & $49.77 \pm 1.90^{\mathrm{a}}$ & $2.93 \pm 1.89^{\mathrm{c}}$ & $30.87 \pm 2.40^{\mathrm{c}}$ & - \\
Control & $82.51 \pm 2.07^{\mathrm{b}}$ & $-0.93 \pm 0.98^{\mathrm{b}}$ & $28.67 \pm 1.12^{\mathrm{b}}$ & $33.07 \pm 2.13^{\mathrm{a}}$ \\
CA & $83.27 \pm 2.03^{\mathrm{b}}$ & $-2.37 \pm 0.65^{\mathrm{a}}$ & $27.07 \pm 2.92^{\mathrm{b}}$ & $34.25 \pm 2.05^{\mathrm{a}}$ \\
CAOD 20\% & $83.62 \pm 1.90^{\mathrm{b}}$ & $-2.23 \pm 0.40^{\mathrm{a}}$ & $24.30 \pm 0.91^{\mathrm{a}}$ & $34.83 \pm 1.85^{\mathrm{a}}$ \\
CAOD 60\% & $82.58 \pm 2.20^{\mathrm{b}}$ & $-1.43 \pm 0.55^{\mathrm{b}}$ & $24.39 \pm 1.48^{\mathrm{a}}$ & $33.76 \pm 2.17^{\mathrm{a}}$ \\
\hline
\end{tabular}

*Mean \pm Standard deviation $(\mathrm{n}=3)$.

**Statistical analysis showing different letter $(\mathrm{a}, \mathrm{b}, \mathrm{c})$ on the same column are significantly different at $\mathrm{p}<0.05$ by Duncan multiple-range test using SPSS statistics software.

\section{Effect of pre-treatment on vitamin $C$}

Pineapple is a tropical fruit that is high in vitamin C content, as well as other micronutrients. Because of its critical function in human physiology and body metabolism, vitamin C (Lascorbic acid) has outstanding nutritional qualities. It has a variety of beneficial functions in the human body, including acting as a strong antioxidant to prevent lipid peroxidation and a strong free radical scavenging agent to remove different types of harmful free radicals from the body; it may also serve as an anti-oxidant (Sarkar et al., 2020).

In this study, the control sample showed the highest retention of vitamin $C$ at $3.08 \pm 0.0021$, followed by CAOD $60 \%$, CAOD $20 \%$, and CA at $2.91 \pm 0.0012,2.64 \pm 0.0005$, and $2.45 \pm 0.0007$, respectively. This result is in agreement with the previous study, which demonstrates that addition of sugar solution resulted in vitamin $\mathrm{C}$ degradation, as compared with the control group. The osmotic process involves immersing the food in a hypertonic solution that helps the mass transfer from fruit tissue to the surrounding water. This situation will result in the soluble vitamin $\mathrm{C}$ to leave the fruit early and reduce the amount of vitamin retention in the finished product.

Previous research in various types of solutions such as trehalose, sodium chloride, sucrose, and fructose shows that sucrose solution has a significant protective impact on ascorbic acid loss during drying and that the lower vitamin $C$ value could be due to ascorbic acid leaching out during soaking the pineapple in sugar solution, as vitamin $\mathrm{C}$ is a water-soluble nutrient. However, this research demonstrates that osmotic solution still has a beneficial impact on pre-treatment of pineapple before drying, but the effect is not statistically significant when compared with control samples. Sarkar et al. (2020) also found that original pineapple fruit slices without any treatment showed the highest retention of vitamin C compared with treated pineapple. 


\section{Effect of pre-treatment on TPC, TFC, and antioxidant activity of freeze-dried MD2 pineapple}

Table 3 shows the total phenolics content (TPC) and total flavonoid content (TFC). TPC varied significantly with sugar concentration, ranging from $3.41 \pm 0.03$ to $3.86 \pm 0.02 \mathrm{mg} \mathrm{GAE} / \mathrm{g}$ DW. Control and CA showed higher yield of TPC compared with other treatment. The presence of osmotic solution with various concentration of sugar showed least retention of TPC in CAOD $60 \%$ and CAOD 20\% (3.42 $\pm 0.12,3.41 \pm 0.03$ mg GAE/g DW), respectively. This finding corroborates the findings of Siriamornpun et al. (2015), who observed that osmotic treatment reducing the TPC compared to other sample for both papaya $(512.91 \pm 20.62,63.22 \pm 9.12 \mu \mathrm{g}$
GAE/g DW) and tomato (330.11 $\pm 10.80,43.32$ $\pm 2.19 \mu \mathrm{g}$ GAE/g DW) for control and treated with sucrose solution prior hot air drying, respectively. Furthermore, they clarify that osmotic treatment may involve the degradation or decomposition of certain phenolic compounds, depending on their chemical structure, since the fruits were placed in hypertonic solution and caused biochemical changes. The mechanism could be explained for TPC loss at concentration of sugar or other pre-treatment and drying process. Since soaking or dipping in osmotic solution are pre-treatment that influences the mass transfer of sugar solution, soluble nutrients such as sugar, minerals and vitamins are expected to be loss during this process (Paula \& Landim, 2016).

Table 3. Effects of different pre-treatment techniques on the phytochemical contents (vitamin C, total phenolic content, total flavonoid content) of freeze-dried MD2 pineapples.

\begin{tabular}{cccc}
\hline Samples & Vitamin C $(\mathbf{m g} / \mathbf{g})$ & $\begin{array}{c}\text { TPC }(\mathbf{m g ~ G A E} / \mathbf{g} \\
\mathbf{D W})\end{array}$ & $\begin{array}{c}\text { TFC (mg rutin/g } \\
\mathbf{D W})\end{array}$ \\
\hline Control & $3.08 \pm 0.0021^{\mathrm{d}}$ & $3.86 \pm 0.02^{\mathrm{c}}$ & $0.14 \pm 0.01^{\mathrm{b}}$ \\
CA & $2.45 \pm 0.0007^{\mathrm{a}}$ & $3.84 \pm 0.01^{\mathrm{c}}$ & $0.14 \pm 0.01^{\mathrm{b}}$ \\
CAOD 20\% & $2.64 \pm 0.0005^{\mathrm{b}}$ & $3.41 \pm 0.03^{\mathrm{b}}$ & $0.12 \pm 0.01^{\mathrm{a}}$ \\
CAOD 60\% & $2.91 \pm 0.0012^{\mathrm{c}}$ & $3.42 \pm 0.12^{\mathrm{a}}$ & $0.11 \pm 0.01^{\mathrm{a}}$ \\
\hline
\end{tabular}

*Mean \pm Standard deviation $(\mathrm{n}=3)$.

**Statistical analysis showing different letter $(\mathrm{a}, \mathrm{b}, \mathrm{c}, \mathrm{d})$ on the same column are significantly different at $\mathrm{p}<0.05$ by Duncan multiple-range test using SPSS statistics software.

The TFC varied from $0.11 \pm 0.01$ to $0.14 \pm 0.01$ $\mathrm{mg}$ rutin/g DW. The control sample retained the most TFC significantly after freeze drying, followed by CA, CAOD 20\%, and CAOD 60\%. It was observed that there is a significance difference $(p<0.05)$ between sample that was treated with and without osmotic solution. Siriamornpun et al. (2015) reported that control dried papaya and dried tomatoes had a remarkable significantly higher content of TFC with values of $57.91 \pm 1.82$ and $33.36 \pm 4.90 \mu \mathrm{g}$ RE/g DW, respectively. The essence of plant matrix and chemistry of bioactive compounds can also influence the retention of flavonoids or other bioactive compounds. TPC and TFC are rather consistent with the increasing trend of osmotic solution that causes the uptake of soluble nutrient in fruit, therefore, decreasing the bioactive compound after freeze drying.

Figure 1 shows the graph line of inhibitory concentration $\left(\mathrm{IC}_{50}\right)$ on the antioxidant activity of standard (L-ascorbic acid) and freeze-dried MD2 pineapple through DPPH method, while Table 4 shows the value of $\mathrm{IC}_{50}$. Lower $\mathrm{IC}_{50}$ values has been characterised with higher antioxidant power. Ascorbic acid is a standard for antioxidant activity and it was observed as the lowest $\mathrm{IC}_{50}$, since it is higher in free radical scavenging activity. The mechanism of DPPH method is occurred when the antioxidant transfer the hydrogen atom to scavenge DPPH free radical. Free radical which is in deep violet colour will change to yellow colour once the free radical is scavenged (Hossain \& Rahman, 2011). The degree of discoloration shows the scavenging abilities of the antioxidant sample. Samples can be classified as very strong, strong, medium, or weak antioxidant, with the range of lower than $50 \mathrm{mg} / \mathrm{L}, 50-100 \mathrm{mg} / \mathrm{L}, 101-$ $150 \mathrm{mg} / \mathrm{L}$, and more than $150 \mathrm{mg} / \mathrm{L}$, respectively (Fidrianny et al., 2018).

The antioxidant capacity of pineapple after freeze drying was found to decrease in order, beginning from CAOD $60 \%$, CAOD $20 \%$, CA, and control at $85.85 \pm 5.93,101.17 \pm 17.00$, 
$163.62 \pm 23.90$, and $172.97 \pm 18.23$, respectively. Unlike others, CAOD 60\% was found to have the highest free radical scavenging activity. According to Almeida et al. (2015), using a high concentration of osmotic solution resulted in a higher preservation of antioxidant activity because the protective effect on the fruit's surface, aided by the inclusion of sucrose in the product, which prevented the outflow of antioxidant activity. Thus, the previous study in osmotic dehydration for banana fruit that was pretreated with three concentrations of sucrose $(45 \%, 50 \%$, and $60 \%)$ supported this finding, where CAOD $60 \%$ of sugar solution reached a higher free radical scavenging activity among other treatments.

\section{Antioxidant activity (DPPH)}

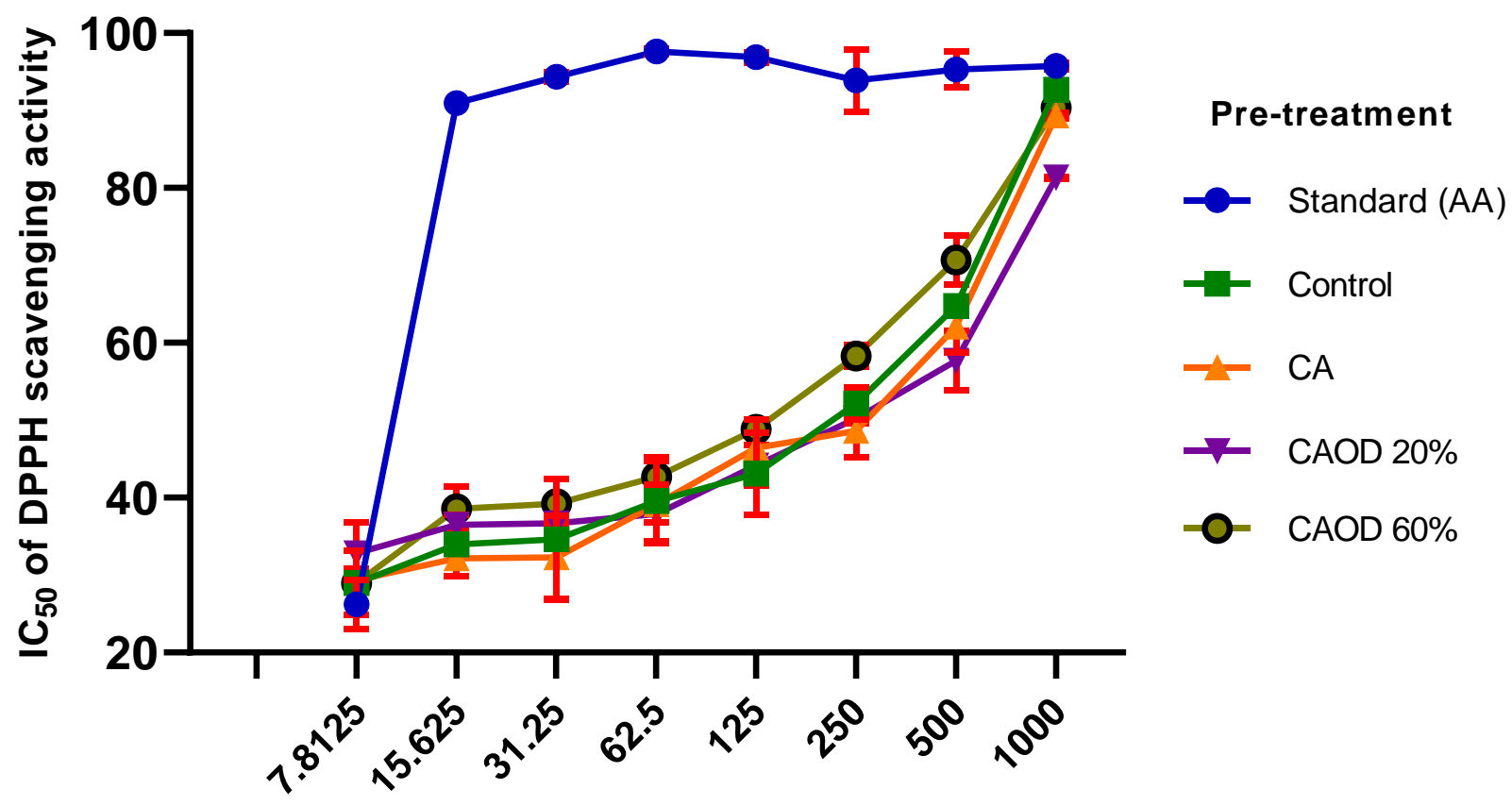

\section{Concentration $(\mathrm{mg} / \mathrm{L})$}

Figure 1. $\mathrm{IC}_{50}$ of DPPH scavenging activity with different pre-treatment of freeze-dried MD2 pineapples.

Table 4. Effects of different pre-treatments on antioxidant activity of freeze-dried MD2 pineapples.

\begin{tabular}{cc}
\hline Samples & DPPH $\left.\mathbf{~ I C ~}_{50}\right)$ \\
\hline Standard (Ascorbic Acid) & $8.97 \pm 0.19$ \\
Control & $172.97 \pm 18.23^{\mathrm{b}}$ \\
CA & $163.62 \pm 23.90^{\mathrm{b}}$ \\
CAOD 20\% & $101.17 \pm 17.00^{\mathrm{a}}$ \\
CAOD 60\% & $85.85 \pm 5.93^{\mathrm{a}}$ \\
\hline
\end{tabular}

*Mean \pm Standard error $(\mathrm{n}=3)$.

**Statistical analysis showing different letter $(\mathrm{a}, \mathrm{b})$ on the same column are significantly different at $\mathrm{p}<0.05$ by Duncan multiplerange test using SPSS statistics software.

\section{CONCLUSION}

The impact of different pre-treatment on physicochemical, phytochemical content, and biological activities of freeze-dried MD2 pineapple were investigated. Osmotic dehydration in $60 \%$ sugar solution with $1 \%$ citric acid (CAOD $60 \%$ ) was recommended as the most preferred pre-treatment condition for the freeze-dried 
pineapple. The least moisture content led to delayed microbial growth, deterioration of dried fruit, and changes of colour, which can preserve the colour in a long-term storage. On the other hand, increased concentration of solution can lead to increased coefficient of water mass transfer between the fruit and the osmotic solution. This study found that the absence of osmotic solution (control and CA) had caused the phytochemical content (Vitamin C, TPC, and TFC) to exert a positive influence in these responses. However, CAOD $60 \%$ shows a positive effect on the antioxidant activity, which resulted in the lowest $\mathrm{IC}_{50}$ compared with that in other samples. This study suggests for shelf life extension to ensure osmotic dehydration treatment helps in preserving the sensory, increasing the quality of dehydrated fruit, and retaining the bioactive compounds. Optimisation on pretreatment conditions, such as time, concentration of solutes, and solid-to-liquid ratio variables, may be a research topic of interest in the future. In conclusion, dried fruit promotes beneficial nutritional, antioxidant, and enzyme properties, and is a good alternative for reducing overharvesting of product waste, particularly during off-season.

\section{ACKNOWLEDGEMENTS}

This study was supported by Ministry of Higher Education and Universiti Teknologi Malaysia under High Impact Research (HIR) grants: Q.J130000.2409.04G25; Q.J130000.2409.04G23.

\section{CONFLICT OF INTEREST}

The authors have declared that no conflict of interests exists.

\section{REFERENCES}

Almeida, J. A. R., Mussi, L. P., Oliveira, D. B., \& Pereira, N. R. 2015. Effect of temperature and sucrose concentration on the retention of polyphenol compounds and antioxidant activity of osmotically dehydrated bananas. Journal of Food
Processing and Preservation 39: 1061-1069.

Amami, E., Khezami, W., Mezrigui, S., Badwaik, L. S., Kammoun, A., Tellez, C., \& Kechaou, N. 2017. Ultrasonics sonochemistry effect of ultrasound-assisted osmotic dehydration pretreatment on the convective drying of strawberry. Ultrasonics - Sonochemistry 36: 286-300.

Ano, M. Y., Ato, M. K., Koma, Y. I., Awasaki, A. K., \& Ukazawa, Y. F. 2005. Quantitation of carotenoids in raw and processed fruits in Japan. Food Science and Technology Research 11(1): 13-18.

Bourdoux, S., Li, D., Rajkovic, A., Devlieghere, F., \& Uyttendaele, M. 2016. Performance of drying technologies to ensure microbial safety of dried fruits and vegetables. Food Science and Food Safety 15: 1056-1066.

Doymaz, Ä. 2009. Effect of citric acid and blanching pretreatments on drying and rehydration of Amasya red apples. Food and Bioproducts Processing 88(2-3): 124-132.

Fidrianny, I., Virna, V., \& Insanu, M. 2018. Antioxidant potential of different parts of Bogor pineapple (Ananas Comosus [L.] merr . var . queen) cultivated in West Java-Indonesia. Asian Journal of Pharmaceutical and Clinic Reseach 11(1): 129-133.

Fratianni, A., Albanese, D., Mignogna, R., Cinquanta, L., Panfili, G., \& Matteo, M. Di. 2013. Degradation of carotenoids in apricot (Prunus armeniaca L .) during drying process. Plant Foods for Human Nutrition 68: 241-246.

Harguindeguy, M., \& Fissore, D. 2019. On the effects of freezedrying processes on the nutritional properties of foodstuff : A review. Drying Technology: 1-23.

Heras-Ramírez, M. E., Quintero-Ramos, A., Camacho-Dávila, A. A., Talamás-Abbud, J. B. \& R., Torres-Muñoz, J. V., \& Salas-Muñoz, E. 2012. Effect of blanching and drying temperature on polyphenolic compound Stability and antioxidant capacity of apple pomace. Food Bioprocess Technology 5(6): 2201-2210.

Hossain, M. A., \& Rahman, S. M. M. 2011. Total phenolics , flavonoids and antioxidant activity of tropical fruit pineapple. Food Research International 44(3): 672-676.

Hwa, C., Lim, C., Cloke, M., Lik, C., \& Chuah, L. 2008. Drying kinetics and product quality of dried Chempedak. Journal of Food Engineering 88: 522-527.

Karim, O. R., Awonorin, S. O., Sanni, L. O., \& Campus, Y. 2008. Effect of pretreatments on quality attributes of airdehydrated pineapple slices. Journal of Food Technology 6(4): 158-165.

Khoo, H., Prasad, K. N., Kong, K., Jiang, Y., \& Ismail, A. 2011. Carotenoids and their isomers: Color pigments in fruits and vegetables. Molecules 16: 1710-1738.

Korekar, G., Dolkar, P., Singh, H., Srivastava, R. B., \& Stobdan, T. 2014. Variability and the genotypic effect on antioxidant activity, total phenolics, carotenoids and ascorbic acid content in seventeen natural population of Seabuckthorn (Hippophae rhamnoides L.) from trans-Himalaya. LWT - Food Science and Technology 55(1): 157-162.

Kumar, P. S., \& Sagar, V. R. 2014. Drying kinetics and physicochemical characteristics of osmo- dehydrated mango, guava and aonla under different drying conditions. Journal of Food Science and Technology (December): 1540-1546.

Kurozawa, L. E., Terng, I., Hubinger, M. D., \& Park, K. J. 2014. Ascorbic acid degradation of papaya during drying: Effect of process conditions and glass transition phenomenon. Journal of Food Engineering 123: 157-164.

Lima, M. M. de, Tribuzi, G., Souza, J. A. R. de, Souza, I. G. de, Laurindo, J. B., \& Carciofi, B. A. M. 2016. Vacuum impregnation and drying of calcium-fortified pineapple snacks. LWT - Food Science and Technology 72: 501-509.

Luximon-Ramma, A., Theeshan Bahorun, Soobrattee, M. A., \& Okezie I. Aruoma. 2002. Antioxidant activities of phenolic, proanthocyanidin, and flavonoid components in extracts of 
Cassia fistula. Journal Agricultural and Food Chemistry 50: 50425047.

Nicoleti, J. F., Jr, V. S., Telis-Romero, J., \& Telis, V. R. N. 2007. Influence of drying conditions on ascorbic acid during convective drying of whole persimmons. Drying Technology : An International Journal 25: 891-899.

Ong, S. P., Law, C. L., \& Hii, C. L. 2012. Effect of pre-treatment and drying method on colour degradation kinetics of dried salak fruit during storage. Food Bioprocess Technology 5: 23312341.

Oyinloye, T. M., \& Yoon, W. B. 2020. Effect of freeze-drying on quality and grinding process of food produce: A review. Processes 8(354): 1-23.

Paula, A., \& Landim, M. 2016. Influence of osmotic dehydration on bioactive compounds, antioxidant capacity, color and texture of fruits and vegetables: a review. Ciência Rural, Santa Maria 46(10): 1714-1722.

Phisut, N. 2012. Spray drying technique of fruit juice powder: some factors influencing the properties of product. International Food Research Journal 19(4): 1297-1306.

Raquel P. F., \& Guinéa, M. J. B. 2012. Effect of drying treatments on texture and color of vegetables (pumpkin and green pepper). Food and Bioproducts Processing 90: 58-63.

Sarkar, T., Salauddin, M., Kumar, S., \& Chakraborty, R. 2020. The impact of raw and differently dried pineapple (Ananas comosus) fortification on the vitamins, organic acid and carotene profile of dairy rasgulla (sweetened cheese ball). Heliyon 6: e05233.

Siriamornpun, S., Ratseewo, J., Kaewseejan, N., \& Meeso, N. 2015. Effect of osmotic treatments and drying methods on bioactive compounds in papaya and tomato. RSC Advances View 5: 18579-18587.

Valentina, V., Pratiwi, R. A., Hsiao, P. Y., Tseng, H. T., , Hsieh J. F., \& Chen, C. C. 2016. Sensorial characterization of foods before and after. Austin Food Sciences 1(6): 1-5.

Yildiz, G., \& Izli, G. 2019. The effect of ultrasound pretreatment on quality attributes of freeze-dried quince slices: Physical properties and bioactive compounds. Journal of Food Process Engineering 42(5): 1-8.

Zapata, J. E., Arias, J. M., \& Ciro, G. L. 2011. Optimization of osmotic dehydration of pineapple (Ananas comosus L.) using the response surface methodology. Physiology \& Post-Harvest Technology 29(2): 249-256.

Zhao, J.-H., Xiao, H.-W., Ding, Y., Nie, Y., Zhang, Y., Zhen, Z., \& Xuan-Ming, T. 2017. Effect of osmotic dehydration pretreatment and glassy state storage on the quality attributes of frozen mangoes under long-term storage. Journal of Food Science and Technology 54(6): 1527-1537.

Zzaman, W., Biswas, R., \& Hossain, M. A. 2021. Application of immersion pre-treatments and drying temperatures to improve the comprehensive quality of pineapple (Ananas comosus) slices. Heliyon 7(8): e05882. 